\title{
TU/e EN⿴HONE

\section{Monolithically integrated array of widely tunable laser sources for multispecies gas sensing applications}

\section{Citation for published version (APA):}

Latkowski, S., Hänsel, A., Bhattacharya, N., de Vries, T., Augustin, L., Williams, K., Smit, M., \& Bente, E. (2016). Monolithically integrated array of widely tunable laser sources for multispecies gas sensing applications. In 2016 Optical Fiber Communication Conference (OFC 2016), 20-24 March, 2016, Anaheim, California [W4H.2] Optical Society of America (OSA). https://doi.org/10.1364/OFC.2016.W4H.2

DOI:

10.1364/OFC.2016.W4H.2

Document status and date:

Published: 20/03/2016

\section{Document Version:}

Accepted manuscript including changes made at the peer-review stage

\section{Please check the document version of this publication:}

- A submitted manuscript is the version of the article upon submission and before peer-review. There can be important differences between the submitted version and the official published version of record. People interested in the research are advised to contact the author for the final version of the publication, or visit the $\mathrm{DOI}$ to the publisher's website.

- The final author version and the galley proof are versions of the publication after peer review.

- The final published version features the final layout of the paper including the volume, issue and page numbers.

Link to publication

\section{General rights}

Copyright and moral rights for the publications made accessible in the public portal are retained by the authors and/or other copyright owners and it is a condition of accessing publications that users recognise and abide by the legal requirements associated with these rights.

- Users may download and print one copy of any publication from the public portal for the purpose of private study or research.

- You may not further distribute the material or use it for any profit-making activity or commercial gain

- You may freely distribute the URL identifying the publication in the public portal.

If the publication is distributed under the terms of Article 25fa of the Dutch Copyright Act, indicated by the "Taverne" license above, please follow below link for the End User Agreement:

www.tue.nl/taverne

Take down policy

If you believe that this document breaches copyright please contact us at:

openaccess@tue.nl

providing details and we will investigate your claim. 


\title{
Monolithically integrated array of widely tunable laser sources for multispecies gas sensing applications
}

\author{
Sylwester Latkowski, ${ }^{1 *}$ Andreas Hänsel, ${ }^{2}$ Nandini Bhattacharya, ${ }^{2}{ }^{\text {Tjibbe de } \text { Vries }}{ }^{1}$, Luc Augustin,, 3 \\ Kevin Williams, ${ }^{1}$ Meint Smit ${ }^{1}$ and Erwin Bente ${ }^{1}$ \\ ${ }^{1}$ COBRA Research Institute, Department of Electrical Engineering, Eindhoven University of Technology \\ PO Box 513, 5600 MB Eindhoven, The Netherlands \\ ${ }^{2}$ TU Delft, Optics Research Group, Van der Waalsweg 8, 2628 CH Delft, The Netherlands \\ ${ }^{3}$ SMART Photonics, Horsten 1, 5612 AX Eindhoven, The Netherlands \\ *S.Latkowski@tue.nl
}

\begin{abstract}
Monolithic integration of four widely tunable extended cavity lasers suitable for gas detection is presented. Each laser features a precise, grid-less tuning mechanism with a lowlinewidth, single-mode output over a wide wavelength range of $74 \mathrm{~nm}$.

OCIS codes: (140.3600) Lasers, tunable; (250.5300) Photonic integrated circuits; (300.1030) Absorption
\end{abstract}

\section{Introduction}

We report on a successful demonstration of a monolithically integrated array of tunable lasers designed for gas sensing applications. The array has four of such independently tunable laser sources combined to a common output. The photonic integrated circuit (PIC) chip has been designed following a generic integration approach [1] and fabricated as a standard $4 \times 4.3 \mathrm{~mm}$ cell within a Multi-Project Wafer (MPW) run by SMART Photonics [2] via Jeppix [3] services. In a gas detection scheme based on single absorption line a widely and precisely tunable single frequency / continues wave $(\mathrm{CW})$ lasers are desired. A few of such independently tunable lasers allow to assess a number of gas species (a gas mixture) simultaneously. The integrated lasers feature a wide and precise wavelength tuning mechanism achieved by a three stage intra-cavity filter formed by asymmetric Mach-Zehnder interferometers (AMZI) using voltage controlled electro-refractive phase modulators (ERM) [4]-[6]. An individual extended cavity ring laser with such wavelength filter shows an single-mode output with optical linewidth of $363 \mathrm{kHz}$, average power of $3 \mathrm{~mW}$ (ex-facet) and a record tuning range of $74.3 \mathrm{~nm}$. Precision of the tuning mechanism a gas spectroscopy is demonstrated by a scan over a $0.89 \mathrm{GHz}$ wide absorption line of acetylene with resolution of $6 \mathrm{MHz}$ (48 fm). Both wide and precise tuning are achieved with only four control voltages wile current injection into the gain section is constant. The reverse biased ERMs operate at low currents therefore control signals do not lead to additional thermal crosstalk on chip. A fully functional PIC realized using active-passive monolithic integration on indium phosphide (InP) including four of such lasers combined to a single output suitable for simultaneous multispecies gas sensing is presented.

\section{Array of widely tunable lasers on a single chip}

Taking advantage of the photonic integration four of widely tunable extended cavity lasers have been co-integrated on a single chip as presented schematically in Fig. 1(a). Optical signals from the output of each laser are combined using a 2x2 MMI based combiner providing with four common output waveguides. Three waveguides are routed to the angled ( $7^{\circ}$ with respect to the normal) outputs at the cleaved and anti-reflection (AR) coated facets of the chip.
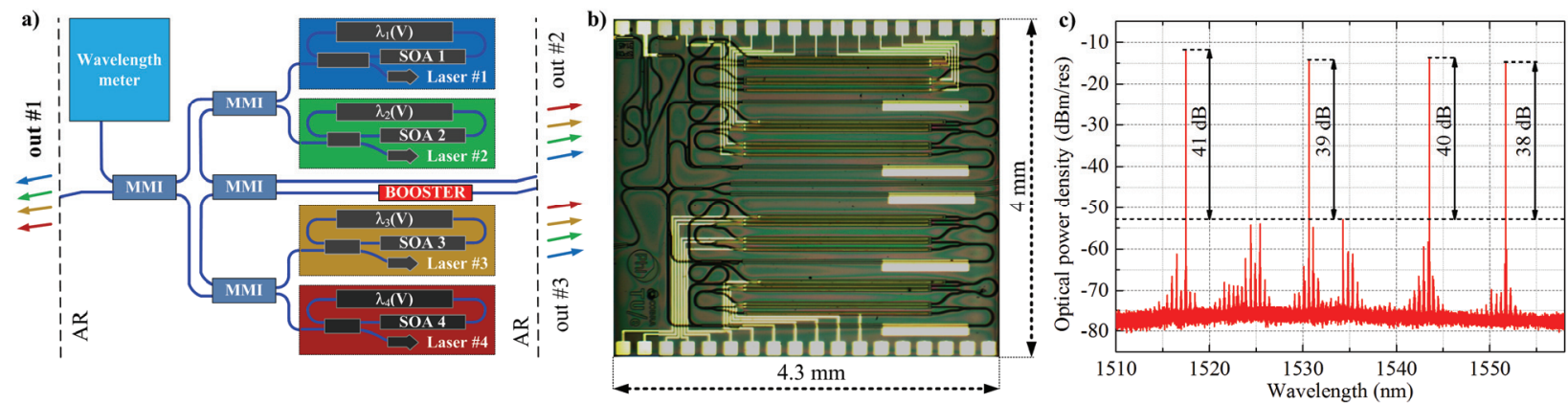

Fig. 3. (a) Schematic diagram of integrated array of tunable lasers featuring: four individual extended ring cavity tunable laser sources (Laser \#n) with voltage controlled wavelength tunable intra-cavity filters $(\lambda(\mathrm{V}))$, $2 \times 2$ MMI base combiner, on-chip wavelength meter and a booster semiconductor optical amplifier (BOOSTER) in one output line. (b) Micrograph of a $17 \mathrm{~mm}^{2}$ chip fabricated within a MPW run. (c) High resolution $(20 \mathrm{MHz}$ ) optical spectrum recorded at the non-amplified common outputs (out \#1) of the chip with gain section of each of the lasers dc biased at $\mathrm{I}_{\mathrm{SOA} \mathrm{N}}=120 \mathrm{~mA}$ and chip operated at room temperature. 
An additional booster semiconductor optical amplifier (SOA) was placed in one common output (out \#3). The fourth common waveguide is directed to an on-chip wavelength meter. The full layout of the PIC fits into a single, standard MPW cell. The $17 \mathrm{~mm}^{2}$ device shown in Fig. 1(b) was fabricated by SMART Photonics within a multi-project wafer run. The optical output from the chip (out\#1) was collected using a lensed fiber (coupling loss $\sim 4 \mathrm{~dB}$ ) followed by a fiberized optical isolator. An optical spectrum recorded with a high resolution $(20 \mathrm{MHz})$ optical spectrum analyzer (OSA) from one of the non-amplified common outputs (out \#1) is presented in Fig. 1(c). The SOA sections of each of the lasers were injected with the same dc current $\left(\mathrm{I}_{\mathrm{SOA} 1}=\mathrm{I}_{\mathrm{SOA} 4}=\mathrm{I}_{\mathrm{SOA} 4}=\mathrm{I}_{\mathrm{SOA} 4}\right)$ of $140 \mathrm{~mA}$ at the chip was maintained at the room temperature $\left(\mathrm{T}_{\mathrm{HEATSINK}}=18^{\circ} \mathrm{C}\right)$. The wavelength filters $\lambda(\mathrm{V})$ with ERM sections in each laser were reverse biased in order to present an arbitrary selection of single-mode operating points, spanning over the wavelength range taking into account accessible bandwidth of the high resolution OSA which was used to confirm single mode-operation. Each of the spectral lines features at least $38 \mathrm{~dB}$ of suppression with respect to the strongest mode present in the spectrum and not being a lasing mode of another laser in the array. The combined output power coupled into the lensed fiber was measured at $2 \mathrm{~mW}$ leading to ex-facet power of $\sim 5 \mathrm{~mW}$ (assuming $4 \mathrm{~dB}$ of fiber coupling loss).

\section{Widely tunable extended cavity ring laser}

Each of the integrated on-chip, wavelength tunable, extended cavity ring laser features a wavelength tuning mechanism based on a combination of asymmetric Mach-Zehnder interferometers [4]. The $16.7 \mathrm{~mm}$ long laser cavity shown in Fig.2(a) features a $1 \mathrm{~mm}$ long semiconductor optical amplifier, deeply etched passive waveguides indicated in blue, a $2 \times 1$ multi-mode interference output coupler and a three stage serial AMZI based wavelength filter. Each AMZI stage is formed by a pair of $1 \times 2$ MMIs with phase modulators in both branches. The laser design in the form of photonic integrated circuit is fully compatible with the generic integration approach.
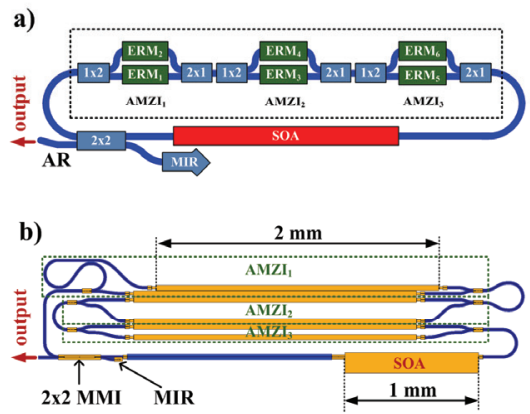

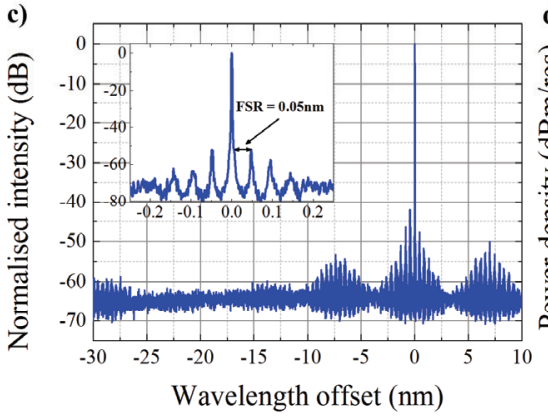

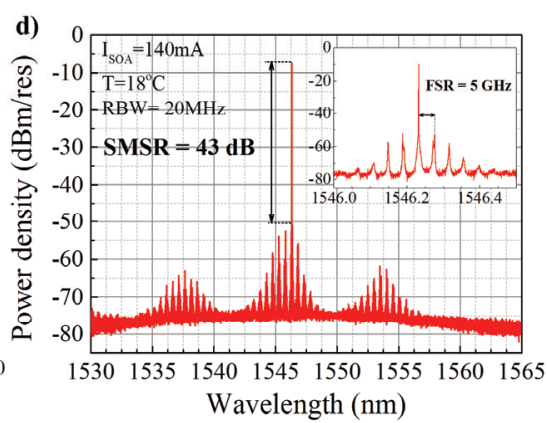

Fig. 2. (a) Schematic diagram and (b) mask layout of the tunable extended cavity ring laser featuring: $1 \mathrm{~mm}$ long semiconductor optical amplifier (SOA), deeply etched passive waveguides indicated in blue, 2x2 MMI output coupler and three stage asymmetric Mach-Zehnder interferometer (AMZI) based filter (dashed box) with each AMZI formed by a pair of 1x2 MMIs with electro-refractive modulators in each branch (EPM). A multimode interference reflector at one of the outputs ensures unidirectional operation of the laser. (c) Simulated output spectrum obtained with a time domain based photonic circuit simulator. Inset: small range $(0.5 \mathrm{~nm})$ showing cavity modes. (d) High resolution (20 MHz) optical spectrum recorded at the output of the laser with the close view at the of the lasing mode showing neighboring cavity resonances presented in the inset.

Numerical studies of such a laser have been carried with use of time domain based photonic circuit simulators [7], [8]. An example of single-mode spectrum obtained from PicWave package [8] is presented in Fig. 2(c). The optical spectra obtained experimentally, recorded with a high resolution $(20 \mathrm{MHz})$ optical spectrum analyzer have confirmed preliminary simulations and demonstrated a single-mode operation with side-mode suppression ratio (SMSR) of $43 \mathrm{~dB}$ as presented in Fig. 2(d). The high resolution spectra allowed to resolve fundamental longitudinal cavity modes spaced by $5 \mathrm{GHz}$ as presented in the inset of Fig. 2(d) [5]. Optical linewidth of the lasing mode has been measured using a delayed self-heterodyne setup [9] with $25 \mathrm{~km}$ of standard single mode fiber and LiNbO3 phase modulator at $363 \mathrm{kHz}$ as presented in Fig. 3(a) with a Lorentzian fit to the measured data shown in red. A tuning range in the excess of $74 \mathrm{~nm}$ was achieved with applying reverse dc bias voltages to four ERMs in the AMZI stages while keeping the current injection into the SOA section $\left(\mathrm{I}_{\mathrm{SOA}}=140 \mathrm{~mA}\right)$ and temperature of the chip $\left(\mathrm{T}_{\text {HEATSINK }}=18^{\circ} \mathrm{C}\right)$ constant as presented in Fig. 3(b). showing a good overlap with preliminary simulations and design objectives [6]. In order to investigate the precision of the wavelength tuning mechanism a gas spectroscopy setup with a reference acetylene cell was used. The optical signal from the isolator was split into two branches: one used as a reference for recording any optical power fluctuations and the other one sent though a reference acetylene cell (Thorlabs CQ09050-CH12: ${ }^{12} \mathrm{C}_{2} \mathrm{H}_{2}, 50$ Torr, $5 \mathrm{~cm}$ ). Both branches were followed by the optical power meters. For the wavelength range calibration optical spectra at each operation point were recorded with a resolution of 20 $\mathrm{MHz}$ (APEX Technologies AP2041A). The transmission profile of the R-branch 9 line of acetylene [10] recorded using the extended cavity ring laser is shown in Fig. 3(c). The absorption spectrum was recorded at 500 points with 
steps of $6.27 \mathrm{MHz}(48 \mathrm{fm})$ performed by applying a consecutive sequence of sets of reverse voltages to the four ERM sections while the SOA bias and temperature of the chip were constant during the experiment. The absorption line features a width of $0.89 \mathrm{GHz}(6.9 \mathrm{pm})$ when measured at $50 \%$ on the logarithmic scale $(\sim 1.2 \mathrm{GHz}$ at full width at half minimum on linear scale).

a)

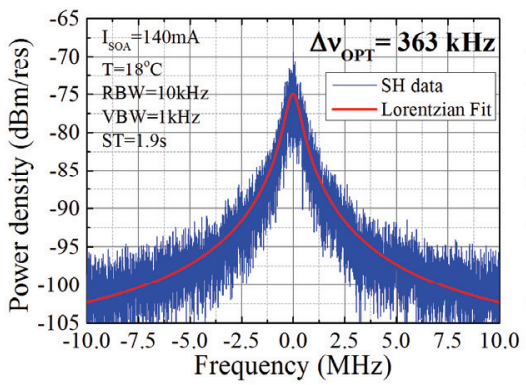

b)

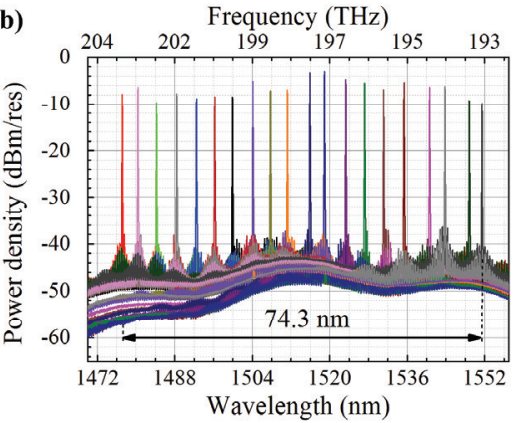

c) Wavelength $(\mathrm{nm})$

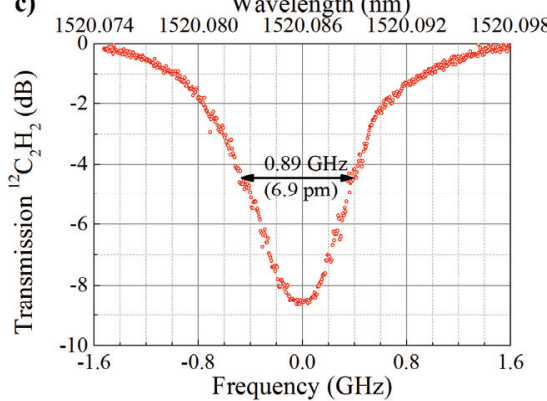

Fig. 3. (a) Optical linewidth of $363 \mathrm{kHz}$ was measured using a delayed self-heterodyne (DSH) method: measurement data and Lorentzian fit are indicated in black and red colors. (b) Overlapped optical spectra recorded with a standard resolution $(0.05 \mathrm{~nm})$ optical spectrum analyzer: SOA section DC biased at $\mathrm{I}_{\mathrm{SOA}}=140 \mathrm{~mA}\left(\sim 2.2\right.$ times of the $\left.\mathrm{I}_{\mathrm{th}}\right)$ at room temperature, showing a tuning range of $74.3 \mathrm{~nm}$. (c) An absorption line of acetylene (R-branch 9th line) measured with the laser tuned by applying a series of reverse bias voltages to the ERM phase sections with the amplifier current $\mathrm{I}_{\mathrm{SOA}}$ set at $125 \mathrm{~mA}$. The $0.89 \mathrm{GHz}$ wide profile was measured with resolution of $6 \mathrm{MHz}(48 \mathrm{fm})$.

\section{Conclusions}

We have demonstrated a fully functional array of individually tunable laser sources fabricated in a multi-project wafer run on an indium phosphide based, generic photonic foundry platform. Each individual extended ring cavity laser features an AMZI based wavelength tunable filter allowing for single-mode operation along with precise access to a record $74 \mathrm{~nm}$ wide tuning range. Presented laser design is suitable for a number of applications including gas spectroscopy, telecommunication and optical coherence tomography. Co-integration of such lasers on a single chip makes it suitable for simultaneous multispecies gas detection and makes such a solution very competitive in terms of footprint and energy consumption when compared with discreet optics based counterparts. Although all four laser have demonstrated to be fully functional when operated at the same time, further investigations have to be carried out in terms of on-chip crosstalk (optical, thermal, electrical) and its impact on the chip's performance.

\section{Acknowledgements}

Presented research is supported by the Technology Foundation STW under the project 11360 LWAVE-TECH and the NRC Photonics program.

\section{References}

[1] M. Smit, X. Leijtens, H. Ambrosius, E. Bente, J. van der Tol, B. Smalbrugge, T. de Vries, E.-J. Geluk, J. Bolk, R. van Veldhoven, L. Augustin, P. Thijs, D. D’Agostino, H. Rabbani, K. Lawniczuk, S. Stopinski, S. Tahvili, A. Corradi, E. Kleijn, D. Dzibrou, M. Felicetti, E. Bitincka, V. Moskalenko, J. Zhao, R. Santos, G. Gilardi, W. Yao, K. Williams, P. Stabile, P. Kuindersma, J. Pello, S. Bhat, Y. Jiao, D. Heiss, G. Roelkens, M. Wale, P. Firth, F. Soares, N. Grote, M. Schell, H. Debregeas, M. Achouche, J.-L. Gentner, A. Bakker, T. Korthorst, D. Gallagher, A. Dabbs, A. Melloni, F. Morichetti, D. Melati, A. Wonfor, R. Penty, R. Broeke, B. Musk, and D. Robbins, "An introduction to InP-based generic integration technology," Semicond. Sci. Technol., vol. 29, no. 8, p. 083001, Jun. 2014.

[2] "SMART Photonics." [Online]. Available: http://www.smartphotonics.nl/.

[3] "Joint European Platform for InP-based Photonic Integrated Components and Circuits." [Online]. Available: http://www.jeppix.eu/. [Accessed: 19-Jun-2014].

[4] S. Latkowski, M. Smit, and E. A. J. M. Bente, "Integrated tunable semiconductor laser geometry based on asymmetric Mach-Zehnder interferometers for gas sensing applications," in Proceedings of the 17th Annual Symposium of the IEEE Photonics Society Benelux Chapter, Mons, Belgium, 2012.

[5] S. Latkowski, T. de Vries, L. Augustin, S. Meint, and E. Bente, "A monolithically integrated tunable single longitudinal mode extended cavity ring laser using Intracavity Mach-Zehnder interferometers.," in Proceedings of the 18th Annual Symposium of the IEEE Photonics Benelux Chapter, Eindhoven, Netherlands, 2013, pp. 97-100.

[6] E. Bente, S. Latkowski, T. de Vries, and M. Smit, "Widely tunable monolithically integrated lasers using intracavity Mach-Zehnder interferometers," in 2014 16th International Conference on Transparent Optical Networks (ICTON), 2014, pp. 1-4.

[7] "PhI circuit simulation - InP PIC simulation software." [Online]. Available: https://sites.google.com/site/inplaserseb/phi-circuit-simulation. [Accessed: 30-Mar-2015].

[8] "PICWave - Photonic IC (PIC) / Laser Diode / SOA Simulator for Active and Passive Devices." [Online]. Available: http://www.photond.com/products/picwave.htm. [Accessed: 16-Feb-2015].

[9] T. Okoshi, K. Kikuchi, and A. Nakayama, "Novel method for high resolution measurement of laser output spectrum," Electron. Lett., vol. 16, no. 16, pp. 630-631, Jul. 1980.

[10] K. Nakagawa, M. de Labachelerie, Y. Awaji, and M. Kourogi, “Accurate optical frequency atlas of the 1.5- $\mu$ m bands of acetylene,” J. Opt. Soc. Am. B, vol. 13, no. 12, p. 2708, Dec. 1996. 